
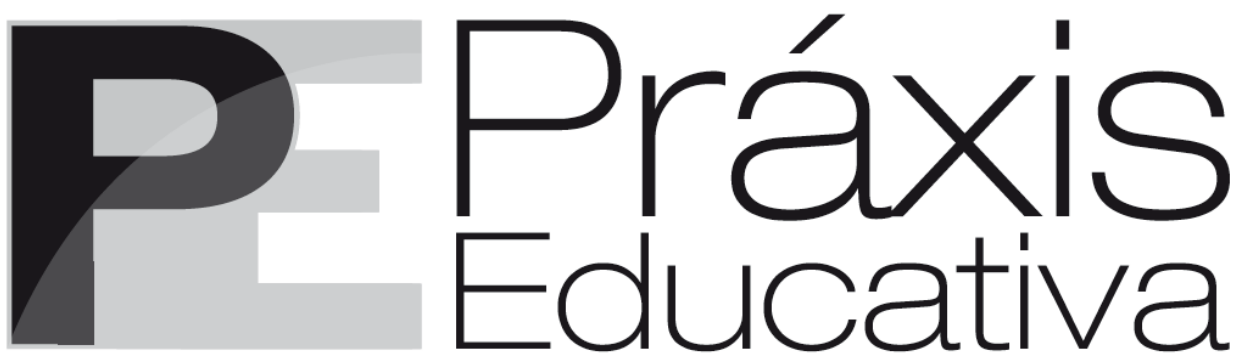

ISSN 1809-4309 (Versão online) DOI: 10.5212/PraxEduc.v.12i2.0015

\title{
Jogos e brincadeiras no desenvolvimento da atenção e da memória em alunos com deficiência intelectual
}

\section{Games and play in the development of attention and memory in students with intellectual disabilities}

\section{Juegos y bromas en el desarrollo de la atención y de la memoria en alumnos con discapacidad intelectual}

\author{
Nerli Nonato Ribeiro Mori* \\ João Paulo dos Passos Santos ${ }^{* *}$ \\ Elsa Midori Shimazaki** \\ Lucyanne Cecilia Dias Goffi ${ }^{* * *}$ \\ Viviane Gislaine Caetano Auada
}

\begin{abstract}
Resumo: Este artigo discute as contribuições dos jogos e das brincadeiras para o processo de desenvolvimento da atenção e da memória em alunos com deficiência intelectual no $1^{\circ}$ ano do Ensino Fundamental. Realizou-se uma pesquisa-ação assim estruturada: em um primeiro momento, elaboraram-se atividades pré-intervenção para verificar a atenção e a memória dos participantes da pesquisa; posteriormente, trabalhou-se com jogos e brincadeiras que contribuíssem para o desenvolvimento das funções psicológicas superiores; e, por fim, aplicou-se uma atividade pós-intervenção com o intuito de observar se houve alterações significativas nas habilidades investigadas. A pesquisa foi levada a efeito em uma escola da região noroeste do Paraná que atende na modalidade de Educação Especial. Participaram da intervenção 8 sujeitos com 6 anos de idade, identificados como deficientes intelectuais. Os resultados evidenciaram que os jogos e as brincadeiras se mostraram como conteúdos eficazes no trabalho pedagógico em relação à memória e, em especial, à atenção.
\end{abstract}

Palavras-chave: Deficiência Intelectual. Atenção. Memória. Jogos. Brincadeiras.

\footnotetext{
* Professora Titular do Departamento de Teoria e Prática da Educação e Programa de Pós-Graduação em Educação da Universidade Estadual de Maringá (UEM). E-mail: <nnrmori@uem.br>.

** Professor da Rede Estadual de Ensino do Paraná. Mestrando do Programa de Pós-Graduação em Educação da Universidade Estadual de Maringá (UEM). E-mail: <jopa_passos@hotmail.com>.

*** Professora do Departamento de Teoria e Prática da Educação e Programa de Pós-Graduação em Educação da Universidade Estadual de Maringá (UEM). E-mail: <emshimazaki@uem.br>.

**** Professora da Rede Estadual de Ensino do Paraná. Doutoranda do Programa de Pós-Graduação em Educação da Universidade Estadual de Maringá (UEM). E-mail: <lucdias@hotmail.com>.

***** Doutoranda do Programa de Pós-Graduação em Educação da Universidade Estadual de Maringá (UEM). Email: <vigcaetano@hotmail.com>.
} 
Jogos e brincadeiras no desenvolvimento da atenção e da memória em alunos com deficiência...

\begin{abstract}
This paper discusses the contributions of games and play to the attention and memory development process within children with intellectual deficiency in the first stage of the second cycle of Basic Education. An action research was conducted with the following structure: at first, pre-intervention activities were undertaken to verify the attention ad memory of the research participants; subsequently, they worked with games and play that contributed towards the development of the higher psychological functions; and, finally, a post-intervention activity was applied in order to observe whether there were significant alterations in the investigated abilities. The research was undertaken in a school in the northwestern region of the state of Paraná, Brazil, which attends Special Education students. Eight children, aged 6 years old, identified with intellectual deficiency, participated in the intervention. The results showed that the games and play proved to have effective contents in the pedagogical work with regard to memory and, in particular, attention.
\end{abstract}

Keywords: Intellectual deficiency. Attention. Memory. Games. Play.

Resumen: En el texto se discuten las contribuciones de los juegos y de las bromas para el proceso de desarrollo de la atención y de la memoria en alumnos con discapacidad intelectual en el primer año de la Enseñanza Primaria. Se realizó una investigación-acción estructurada de la siguiente forma: en un primero momento, se realizaron actividades pre-intervención para verificar la atención y la memoria de los participantes de la investigación; posteriormente, se trabajó con juegos y bromas que contribuyeran para el desarrollo de las funciones psicológicas superiores; y, por fin, se aplicó una actividad post-intervención, con la intención de observar si hubo alteraciones significativas en las habilidades investigadas. La investigación fue llevada a cabo en una escuela de la región noroeste del Paraná que trabaja con Educación Especial. Participaron de la intervención 8 sujetos con 6 años de edad, identificados como deficientes intelectuales. Los resultados evidenciaron que los juegos y las bromas probaron ser contenidos eficaces en el trabajo pedagógico en relación a la memoria y, en especial, a la atención.

Palabras clave: Discapacidad intelectual. Atención. Memoria. Juegos. Bromas.

\title{
Introdução
}

A Educação Física escolar é componente do currículo voltado à formação do cidadão por meio de jogos, brincadeiras, dança, luta, ginástica e esportes. Esses conteúdos referem-se à cultura corporal e podem contribuir para transformar o homem e as estruturas sociais (VÊNANCIO; DARIDO, 2012).

Soares (1996) e Basei (2008) afirmam que os conteúdos da Educação Física, no âmbito escolar, se transformaram para integrar os elementos culturais presentes na sociedade; dessa forma, valorizam as diversas linguagens existentes, tornando-se uma das linguagens específicas do ser humano tematizadas nas escolas. A Educação Física possibilita ainda o resgate da cultura infantil, assim como os jogos e as brincadeiras a ela pertencentes. Por conseguinte, a escola, ao utilizar a cultura local, deve voltar-se à função educativa para tal prática (ANDRÉ; HASTIE; ARAÚJO, 2015).

A educação não pode estar dissociada dos objetivos escolares que entendemos ser, um dos mais primordiais, o desenvolvimento da funções psicológicas superiores, isto é, da linguagem, do raciocínio, da memória, da atenção e da percepção. Na proposta pedagógica da escola, os conteúdos do jogo e da brincadeira não podem ser desconsiderados, uma vez que o jogo e o brincar são instrumentos mediadores dos conhecimentos escolares da Educação Básica (FREIRE, 1989; VENÂNCIO; DARIDO, 2012).

Os jogos e as brincadeiras auxiliam no processo de aprendizagem e no desenvolvimento de crianças com deficiência intelectual que estudam na Educação Básica; no caso desta pesquisa,

Práxis Educativa, Ponta Grossa, v. 12, n. 2, p. 551-569, maio/ago. 2017 Disponível em: <http://www.revistas2.uepg.br/index.php/praxiseducativa> 
alunos que estudam na primeira etapa do primeiro ciclo do Ensino Fundamental ${ }^{1}$. Para verificar tal afirmação, elaboramos como questão de pesquisa: Quais as contribuições dos jogos e das brincadeiras no processo de desenvolvimento da memória e da atenção? Para responder a essa questão, objetivamos verificar as contribuições dos jogos e das brincadeiras para o processo de desenvolvimento da atenção e da memória em alunos com deficiência intelectual na fase inicial do processo de escolarização.

No desenvolvimento das funções psicológicas superiores, escolhemos estudar a memória e a atenção, pois verificamos, nas pesquisas como as de Azevedo (2016), Auada (2015), Cárnio e Shimazaki (2011), que os alunos com deficiência intelectual, muitas vezes, não se apropriam do conhecimento escolar por não terem desenvolvido essas habilidades.

Para efetivar os objetivos propostos, inicialmente abordamos a Educação Física escolar e a Educação Física adaptada. Em seguida, o desenvolvimento das funções superiores. Posteriormente, apresentamos e discutimos a metodologia, os dados e seus resultados. Por fim, tecemos as considerações finais desta pesquisa.

\section{Educação Física escolar e Educação Física adaptada}

A Carta Internacional de Educação Física e Desportes, aprovada pela Conferência da Organização das Nações Unidas (UNESCO), em 21 de novembro de 1978, estabelece que todos possuem direito à Educação Física, tanto no plano educacional quanto em outros aspectos da vida social, com o objetivo de garantir o desenvolvimento das aptidões físicas, intelectuais e morais (SILVA; SEABRA JÚNIOR; ARAÚJO, 2008). Dessa forma, institucionalizou-se a Educação Física como direito de todos e, a partir de então, ela passa a ser um direito de todas as pessoas que estudam tanto no ensino regular como no ensino especial da região urbana ou do campo, moradores de comunidades com características próprias, crianças jovens e adultos.

Quando pensamos na Educação Física escolar geral, no século XXI, e na Educação Física adaptada, logo pensamos no modelo de corpo determinado pela sociedade, ao qual as pessoas com deficiência comumente não atendem, pois seus corpos diferem dos padrões preestabelecidos. Isso não significa que a Educação Física adaptada, por atender às pessoas com deficiência, deve ter função diferenciada da educação ou da Educação Física escolar.

Entendemos que a Educação Física deve, como as demais áreas da educação, buscar alternativas para que todos os que estão nas escolas, especiais ou não, se apropriem do conhecimento escolar. Para isso, é necessário que o professor planeje as suas atividades para intervir no processo de crescimento natural do aluno, para que esse conhecimento seja um instrumento de participação social. A esse respeito, Araújo e Silva (2012) afirmam que não é mais possível desvincular a educação geral da disciplina de Educação Física. Os autores também alertam que a inclusão escolar das pessoas que possuem deficiência também criou a necessidade de fortalecer essa articulação na educação.

Silva, Seabra Júnior e Araújo (2008) explicam que, no campo educacional, é muito importante atentarmos às necessidades educativas especiais, as quais nem sempre estão associadas à deficiência. Elas podem ser entendidas como circunstâncias que distinguem desvantagens do

\footnotetext{
${ }^{1}$ O parecer CEE/CEIF/CEMEP 07/14 estabelece, nas escolas de Educação Básica, na modalidade Educação Especial, a organização escolar por meio de 2 ciclos para o Ensino Fundamental, [...] que equivalem, respectivamente, ao $1 .^{\circ}$ e $2 .^{\circ}$ anos do Ensino Fundamental, sendo que o $1 .^{\circ}$ ciclo está subdividido em quatro etapas, com duração de quatro anos letivos, ou seja, um ano letivo para cada etapa. O $2 .^{\circ}$ ciclo subdividido em seis etapas, com duração de seis anos letivos, ou seja, um ano letivo para cada etapa (PARANÁ, 2014, p. 11).
}

Práxis Educativa, Ponta Grossa, v. 12, n. 2, p. 551-569, maio/ago. 2017 Disponível em: <http://www.revistas2.uepg.br/index.php/praxiseducativa> 
indivíduo, temporárias ou permanentes, motivadas pela diferença entre seu desempenho e as suas expectativas, bem como as do grupo ao qual pertence, nos aspectos biopsicossociais.

São evidentes as contribuições da Educação Física adaptada, seja como área de conhecimento ou como prática de atividade física e desportiva, para as pessoas com deficiência. Nesse sentido, associamos essas contribuições aos progressos da área, tais como o desenvolvimento tecnológico, com construção de materiais específicos para uso em jogos e atividades para esses fins (COSTA; SOUSA, 2004; CASTRO, 2005).

A Educação Física adaptada, assim como a Educação Física escolar, visa ao desenvolvimento das condutas de base (percepção auditiva, visual e tátil; coordenação motora ampla, fina e óculo segmentar), além dos estímulos afetivo, cognitivo e das capacidades físicas (resistência, força, velocidade e agilidade) (COSTA; SOUSA, 2004). Dessa forma, o professor deve preparar suas propostas pedagógicas no ambiente escolar de maneira que contemplem o desenvolvimento integral, nesse caso, da pessoa com deficiência intelectual.

Tanto a Educação Física adaptada quanto a Educação Física escolar precisam conceber o aluno como um ser em processo de crescimento e/ou desenvolvimento, que vivencia o ensino e a aprendizagem em etapas e formas diferentes, sejam por suas características individuais, necessidades, expectativas, sejam por seu interesse. Nesse sentido, é necessário que o docente conheça as implicações das deficiências para não categorizar a pessoa e também para não colocar em risco sua integridade (SILVA; SEABRA JÚNIOR; ARAÚJO, 2008).

O desenvolvimento de mecanismos compensatórios à deficiência pode acontecer por meio da Educação Física adaptada. Nessa direção, Vigotsky ${ }^{2}$ (1997) afirma que a educação dada às pessoas com deficiência deve concentrar-se na compensação, selecionando experiências que possibilitam a formação da pessoa como um todo. Desse modo, deve envidar esforços para transcender a deficiência; assim a educação da pessoa com deficiência intelectual é essencialmente a educação da vitória sobre ela. Nas palavras do Vigotsky (1997), a escola não deve adaptar a deficiência do aluno e sim buscar maneiras de superá-la.

Vigotsky (1997) criticou o treinamento das escolas por meio sensorial e motor em atividades artificiais, isoladas e desinteressantes. $\mathrm{O}$ autor assinala que a escola tem encontrado a solução na integração desses exercícios dentro de atividades de brincadeiras. Quando tornados parte integral de uma atividade atrativa de trabalho, os exercícios perdem o caráter opressivo aos olhos da criança.

As proposições da Teoria Histórico-Cultural fundamentaram nosso trabalho com os jogos e as brincadeiras para a aprendizagem e o desenvolvimento da memória e da atenção em crianças com deficiência. Na Teoria Histórico-Cultural, é possível observar que os aspectos motores e verbais do comportamento estão interligados na atuação humana. Considerando que a fala envolve elementos referenciais e também pode ser orientada por meio (cultura), ela ainda é fundamental para a organização do movimento (LURIA, 2016; VIGOTSKY, 2007). Assim sendo, no tópico a seguir discutimos as contribuições dos jogos e das brincadeiras para o desenvolvimento das funções psicológicas superiores.

\footnotetext{
2 Adotamos, no corpo deste texto, para o autor Lev Semenovich Vigotsky (1896-1934), a grafia "Vigotsky", tendo em vista a frequência dessa forma na tradução brasileira.
}

Práxis Educativa, Ponta Grossa, v. 12, n. 2, p. 551-569, maio/ago. 2017 Disponível em: <http://www.revistas2.uepg.br/index.php/praxiseducativa> 


\section{Jogos e brincadeiras e o desenvolvimento das funções psicológicas superiores}

Para melhor compreendermos as contribuições teóricas dos estudiosos da Teoria Histórico-Cultural acerca da relação entre jogos e brincadeiras e o desenvolvimento psíquico infantil, empreendemos uma breve contextualização histórica sobre essa temática. Jukovskaia (1978) sustenta que foi G. V. Plekhanov, em seus estudos, que criticou severamente a teoria burguesa de que o jogo infantil era manifestado por instintos biológicos, pois defendia a ideia do jogo como "filho" do trabalho.

De acordo com Huizinga (1980), o jogo não pode ser compreendido pela análise biológica; em sua visão, a origem do jogo é uma das noções mais primitivas do homem, pois o jogo antecede a cultura. Todavia, o autor não afirma que a civilização teve origem no jogo por meio de um processo evolutivo, muito menos que o jogo se transforma em cultura, mas sim destaca que as fases primitivas da cultura apresentam um caráter lúdico. "Na dupla unidade do jogo e da cultura, é ao jogo que cabe a primazia" (HUIZINGA, 1980, p. 53). Caillois (1994) discorda, nesse ponto, com o pensamento de Huizinga e assinala que os jogos são provenientes de nossa cultura ancestral, que o jogo está consubstancialmente relacionado à cultura, mas não a antecede.

Os pesquisadores da Teoria Histórico-Cultural, Vigotsky (2003), Leontiev (2006) e Elkonin (1998), entendem que os jogos, assim como as demais atividades humanas, são influenciados pelas relações da sociedade; desse modo, possuem um fundo social, não podendo, portanto, serem tratados como instintos biológicos. Na acepção de Elkonin (1998), o jogo aparece quando há uma mudança no papel que a criança ocupa no sistema social.

Ao recorrerem à obra de Elkonin intitulada A psicologia do jogo, Marcolino, Barros e Mello (2014) ressaltam que o jogo era utilizado em diferentes povos e épocas. No entanto, é importante enfatizar que, nas sociedades primitivas, muitas vezes, não haviam condições suficientes para o surgimento dos jogos protagonizados ou jogos de papéis, porque os pais inseriam seus filhos nas atividades laborais sem preparo adequado.

As contribuições da Psicologia Soviética, de acordo com Faria (2016), mostram que a brincadeira possui conteúdo e estrutura específicos, e o objeto da atividade da criança na brincadeira é o adulto. Dessa forma, os motivos principais da brincadeira estão relacionados com o agir do adulto, mas isso não significa ser um adulto, mas atuar como tal. Isso nos remete à ideia de que o desenvolvimento da brincadeira requer, desde o início, uma ação conjunta entre a criança e o adulto.

Em seus estudos, Leontiev (1978) constatou que a aquisição e a apropriação do conhecimento produzido historicamente pela sociedade, por parte dos sujeitos, não seria possível pela herança biológica, mas sim pela influência dos fenômenos externos, como a cultura intelectual e material. É dessa forma, por meio do convívio social, que a criança, ao nascer, se apropria daquilo que foi produzido historicamente pela sociedade. Esse processo de apropriação acontece a partir da atividade da criança, a qual é envolvida pela mediação de outros sujeitos, que lhe possibilitam a apreensão da sua cultura.

Conforme os autores russos Elkonin (1998) e Leontiev (1978), a atividade principal da criança é aquela em que ocorrem mudanças significativas em seu desenvolvimento psicológico e "[...] dentro da qual se desenvolvem processos psíquicos que preparam o caminho de transição da criança para um novo e mais elevado nível de desenvolvimento" (LEONTIEV, 2006, p. 122). Segundo esses autores, a atividade principal da criança é constituída pelo brincar.

Práxis Educativa, Ponta Grossa, v. 12, n. 2, p. 551-569, maio/ago. 2017 Disponível em: <http://www.revistas2.uepg.br/index.php/praxiseducativa > 
Leontiev (2006) acentua que a percepção que as crianças têm do mundo acaba por ditar o conteúdo de suas brincadeiras, sendo a ação que elas exercem sobre o brinquedo é que o faz interessante, e não exatamente o brinquedo em si. A presença de um mediador, seja um adulto ou uma criança mais velha, nesse processo, é muito importante, pois são eles que vão apresentar à criança o mundo que a cerca. Buscamos esclarecer melhor essa questão na seguinte citação:

\begin{abstract}
Nos objetos não se indicam diretamente os modos de emprego, os quais não podem descobrir-se por si sós às crianças durante a simples manipulação, sem a ajuda, nem a direção dos adultos, sem um modelo de ação. O desenvolvimento das ações com os objetos é o processo de sua aprendizagem sob a direção imediata dos adultos. (ELKONIN, 1998, p. 216).
\end{abstract}

Os jogos e as brincadeiras também assumem outros aspectos de relevância, tais como sociabilidade, cognição e linguagem, as quais são desenvolvidas, por exemplo, no momento em que as crianças formulam regras e desenvolvem estratégias. Ao brincar, as crianças aumentam seu vocabulário conversando com outrem ou mesmo ao conversarem sozinhas, utilizando a imaginação e criando um mundo de faz-de-conta. Nesse mundo imaginário, dialogando com os próprios brinquedos, exercitam, também, a pronúncia das palavras.

A atividade que mais exerce influência no desenvolvimento psicológico da criança é o jogo, que, em sua perspectiva, é importante ainda para a superação do egocentrismo e para o controle da impulsividade, já que é necessário aceitar regras e conviver com o outro na brincadeira. Os jogos e as brincadeiras permitem também a vivência da autonomia, da organização do pensamento, e auxiliam diretamente no desenvolvimento da memória, da atenção e da criatividade, originando, dessa maneira, a formação das funções psicológicas superiores (ELKONIM, 1998).

Nesse sentido, podemos afirmar que tanto as circunstâncias concretas quanto as relações humanas são condicionantes do desenvolvimento infantil. Leontiev (1978) sublinha que, pela comunicação e pela sua atividade, a criança adentra um mundo em que se apropria ativamente dos objetos humanos com os quais reproduz as ações humanas. É pela relação com as pessoas de seu convívio que a criança modifica e constitui seu modo de vida, suas ações, suas relações humanas. O desenvolvimento infantil, portanto, está atrelado ao lugar efetivo que a criança ocupa nas relações sociais.

Elkonin (1998), além de concordar com Leontiev (1978), acrescenta que é por meio do jogo protagonizado (ou jogo de faz-de-conta) e nas brincadeiras que podemos observar a reconstituição das atividades do mundo adulto. Por conseguinte, a aproximação da criança com a atividade dos adultos é um meio para que ela progrida no trabalho escolar.

Em suas investigações, Leontiev (2006) aponta a relação do jogo de faz-de-conta com outras esferas das atividades humanas. Segundo o autor, em uma dessas esferas está o desenvolvimento do jogo, que, em sua visão, tem uma sequência que vai do jogo de faz-de-conta ao estudo e, posteriormente, ao trabalho. Conforme o autor, cada uma dessas atividades possui um caráter de importância de acordo com o desenvolvimento da criança, e, na idade pré-escolar, é o jogo que assume uma significância maior: o jogo antecede e auxilia no desenvolvimento das bases psicológicas mais complexas que darão sustentação ao estudo, o qual, por sua vez, dará suporte a outras modificações posteriores, como, por exemplo, o trabalho.

$\mathrm{Na}$ Teoria Histórico-Cultural, a característica social é vista como a mola propulsora para o desenvolvimento infantil. Nessa linha teórica de desenvolvimento psicológico, os estudos referentes à temática dos jogos e das brincadeiras foram abordados por Vigotsky, Leontiev, 
Elkonin e, posteriormente, por Jukovskaia. Esta última autora faz uma interessante afirmação a respeito de como o brincar contribui para a formação psicológica da criança.

No jogo, as crianças por sua própria vontade, ao imitarem os maiores, tomam para si
um rol de gestos, e às vezes, à sua maneira, desenvolvem criativamente o argumento; à
sua maneira utilizam o objeto lúdico, os brinquedos. Os jogos criativos, ricos em
conteúdo, surgem sobre a base inculcação dos sentimentos, dos interesses e do
desenvolvimento da imaginação. (JUKOVSKAIA, 1978, p. 3 , tradução nossa). ${ }^{3}$

Como pudemos observar até aqui, o jogo é considerado, por esses pressupostos teóricos, como uma atividade de fundamental importância na infância, precedente de outras atividades. Outrossim, está intimamente ligado às relações com o trabalho, com a mediação entre os sujeitos e com as mudanças ocorridas na sociedade, além de uma atividade essencial ao desenvolvimento infantil.

Faria (2016) corrobora com essa ideia quando afirma que, para a Teoria HistóricoCultural, a brincadeira é vista a partir das condições sociais dos sujeitos e não como um fenômeno de origem biológica, ou seja, o jogo protagonizado ou a brincadeira de papéis sociais surgiram conforme as necessidades sociais ao longo da história. Nesse sentido, tendo por base a Teoria Histórico-Cultural, apresentamos e discutimos, no tópico a seguir, os procedimentos metodológicos e as intervenções.

\section{Procedimentos metodológicos}

Para levarmos esta pesquisa a efeito, um conjunto de procedimentos foram adotados. Em primeiro lugar, atender as normas do Conselho Nacional de Saúde, mediante o estabelecido nas Resoluções 466/2012 $2^{4}$ e 510/2016 ${ }^{5}$. Para tanto, a pesquisa ${ }^{6}$ foi submetida e aprovada pelo Comitê Permanente de Ética em Pesquisa com Seres Humanos (COPEP) da Universidade Estadual de Maringá (UEM), por meio do Parecer no. 56479116.0.0000.0104. Em segundo, mas não menos importante, foi a permissão dos pais e/ou responsáveis por meio da assinatura do Termo de Consentimento Livre e Esclarecido (TCLE) para que seus filhos ou dependentes pudessem participar da pesquisa.

- Contexto da pesquisa

A pesquisa foi desenvolvida em uma escola especial de um município da região noroeste do estado do Paraná. Trata-se de uma escola privada de cunho filantrópico, mantida pela Associação de Pais e Amigos dos Excepcionais (APAE), fundada em 1976 e em funcionamento até os dias atuais. Nela estudam 174 alunos com idades que variam entre 0 a 72 anos. Para atender a esses alunos, a escola conta com 27 professores, 1 pedagogo, 3 psicólogos, 1 terapeuta ocupacional, 2 fisioterapeutas e 1 assistente social.

\footnotetext{
${ }^{3}$ En el juego, los niños por su propia voluntad, al imitar a los mayores, toman para sí el rol de éstos y a veces, a su forma, desarollan creativamente el argumento; a su manera, emplean el material lúdicro, los juguetes. Los juegos creativos ricos en contenido, surgen sobre la base del desarollo de la observación, de la memoria, del pensamiento, de la inculcación de los sentimientos, de los intereses y del desarollo de la imaginación. (JUKOVSKAIA, 1978, p. 3).

4 Aprovada pelo Conselho Nacional de Saúde em 12 de dezembro de 2012, atualiza e regulamenta as diretrizes e as normas para pesquisas envolvendo seres humanos (BRASIL, 2012).

${ }^{5}$ Aprovada pelo Conselho Nacional de Saúde em 7 de abril de 2016, apresenta as normas aplicáveis a pesquisas em Ciências Humanas e Sociais (BRASIL, 2016).

${ }^{6}$ A pesquisa faz parte do projeto Linguagem, letramento e diversidade.

${ }^{7}$ Dados obtidos na secretaria da escola no ano letivo de 2016.
}

Práxis Educativa, Ponta Grossa, v. 12, n. 2, p. 551-569, maio/ago. 2017 Disponível em: <http://www.revistas2.uepg.br/index.php/praxiseducativa > 
Jogos e brincadeiras no desenvolvimento da atenção e da memória em alunos com deficiência...

- Materiais utilizados

Os materiais utilizados na coleta de dados foram uma câmera digital da marca Sony, modelo W800, para registrar as fotografias e um diário de campo, para anotar as principais observações dos sujeitos ao realizar as atividades pré e pós-intervenção e durante as aulas.

- Sujeitos da pesquisa

Para a seleção dos sujeitos da pesquisa, utilizamos alguns critérios, tais como:

- Estar matriculado em turma na $1^{\circ}$ etapa do $1^{\circ}$ ciclo do Ensino Fundamental.

- Ser caracterizado como deficiente intelectual.

- Os pais terem assinado o Termo de Consentimento Livre e Esclarecido.

Atenderam aos critérios estabelecidos 8 sujeitos, todos com 6 anos de idade, distinguidos como alunos com deficiência intelectual e outras características (Quadro 1).

Elaboramos o Quadro 1 com os dados do relatório de sua avaliação multiprofissional, por meio da qual houve permissão para que os alunos fossem matriculados na modalidade de Educação Especial, pois possuem deficiência intelectual (DI).

Quadro 1 - Identificação dos sujeitos

\begin{tabular}{|l|l|l|c|}
\hline \multicolumn{1}{|c|}{$\mathbf{N}^{\circ}$} & \multicolumn{1}{c|}{ Identificação } & \multicolumn{1}{c|}{ Informações técnico-pedagógicas } \\
\hline $\begin{array}{l}\text { Sujeito } 1 \\
\text { (S1) }\end{array}$ & $\begin{array}{l}\text { Sexo: Feminino } \\
\text { Idade: } 6 \text { anos }\end{array}$ & $\begin{array}{l}\text { Lentidão difusa da atividade elétrica cerebral; atraso no } \\
\text { desenvolvimento neuropsicomotor; uso de anticonvulsivos. }\end{array}$ \\
\hline $\begin{array}{l}\text { Sujeito } 2 \\
\text { (S2) }\end{array}$ & $\begin{array}{l}\text { Sexo: Feminino } \\
\text { Idade: } 6 \text { anos }\end{array}$ & $\begin{array}{l}\text { Deficit na atenção, memória, concentração, habilidades cognitivas e } \\
\text { linguagem oral; probabilidade de DI e co-morbidade com quadro } \\
\text { psiquiátrico. }\end{array}$ \\
\hline $\begin{array}{l}\text { Sujeito } 3 \\
\text { (S3) }\end{array}$ & $\begin{array}{l}\text { Sexo: Masculino } \\
\text { Idade: } 6 \text { anos }\end{array}$ & $\begin{array}{l}\text { Lentidão difusa da atividade elétrica cerebral; atraso na fala, atenção, } \\
\text { concentração, memória, raciocínio, linguagem oral e corporal; sinais de } \\
\text { atividade irritativa de projeção; imaturidade, insegurança e ansiedade. }\end{array}$ \\
\hline $\begin{array}{l}\text { Sujeito } 4 \\
\text { (S4) }\end{array}$ & $\begin{array}{l}\text { Sexo: Feminino } \\
\text { Idade: } 6 \text { anos }\end{array}$ & $\begin{array}{l}\text { Lentidão difusa da atividade elétrica cerebral; atraso na linguagem oral, } \\
\text { desenvolvimento cognitivo, memória, atenção e neuropsicomotor. }\end{array}$ \\
\hline $\begin{array}{l}\text { Sujeito } 5 \\
\text { (S5) }\end{array}$ & $\begin{array}{l}\text { Sexo: Masculino } \\
\text { Idade: } 6 \text { anos }\end{array}$ & $\begin{array}{l}\text { Deficit no desenvolvimento neuropsicomotor, atenção, concentração, } \\
\text { memória, raciocínio, conceituação espacial, lateralidade e temporal. }\end{array}$ \\
\hline $\begin{array}{l}\text { Sujeito } 6 \\
\text { (S6) }\end{array}$ & $\begin{array}{l}\text { Sexo: Feminino } \\
\text { Idade: } 6 \text { anos }\end{array}$ & $\begin{array}{l}\text { Síndrome de Down por trissomia livre; atraso no desenvolvimento } \\
\text { neuropsicomotor, cognitivo, motor, atenção, concentração, } \\
\text { conceituação espacial e temporal, lateralidade, esquema corporal e } \\
\text { coordenação motora global. }\end{array}$ \\
\hline $\begin{array}{l}\text { Sujeito } 7 \\
\text { (S7) }\end{array}$ & $\begin{array}{l}\text { Sexo: Masculino } \\
\text { Idade: } 6 \text { anos }\end{array}$ & $\begin{array}{l}\text { Espessamento mucoso dos seios maxilares e esfenoidais com bolhas } \\
\text { gasosas no lado direito; sem linguagem expressiva espontânea, } \\
\text { linguagem própria, fala infantilizada, entonação mecânica e dificuldade } \\
\text { de compreensão; brincadeiras solitárias, atraso no desenvolvimento } \\
\text { cognitivo e social; probabilidade de TGD; agitação motora. }\end{array}$ \\
\hline
\end{tabular}




\begin{tabular}{|l|l|l|}
\hline $\begin{array}{l}\text { Sujeito } 8 \\
\text { (S8) }\end{array}$ & $\begin{array}{l}\text { Sexo: Feminino } \\
\text { Idade: } 6 \text { anos }\end{array}$ & $\begin{array}{l}\text { Dificuldade em verbalizar palavras, coordenação motora geral, noção } \\
\text { espacial, concentração, compreensão, atenção concentrada; } \\
\text { memorização, cognição e linguagem oral e corporal; apresenta irritação, } \\
\text { pouca socialização, síndrome epilética. }\end{array}$ \\
\hline
\end{tabular}

Fonte: Elaborado pelos autores com base nas anotações dos relatórios técnico-pedagógicos da instituição. DI $=$ Deficiência Intelectual; TGD $=$ Transtorno Global do Desenvolvimento.

Áreas Técnicas: Psicologia; Psicopedagogia; Terapia Ocupacional; Médico neurologista; Fisioterapia; Fonoaudiologia e Serviço social.

É importante destacar que, diferentemente de outras pesquisas, como as de Cárnio e Shimazaki (2011), Goffi e Mori (2010) e Auada (2015), há a predominância de pessoas do sexo feminino na turma em que realizamos a intervenção pedagógica.

Apesar de as avaliações não demostrarem os critérios utilizados para as informações técnicas e pedagógicas ${ }^{8}$, verificamos que 6 dentre os 8 sujeitos analisados apresentam dificuldades na memória e na atenção. Dessa forma, trabalhamos atividades que desenvolvessem essas habilidades.

\section{Procedimentos e análise}

Preparamos e trabalhamos as intervenções com atividades correspondentes à Educação Física escolar, por meio da cultura corporal de movimento, nos conteúdos de jogos e brincadeiras, que contribuíssem para o desenvolvimento da memória e da atenção. Como assinalamos, esses conteúdos são instrumento para a cidadania e a inclusão. Antes da intervenção, elaboramos uma avaliação inicial e final para verificarmos os possíveis avanços nos conhecimentos dos alunos. Realizamos as intervenções duas vezes por semana, durante 4 meses, com sessões de 50 minutos cada, durante as aulas de Educação Física, ministradas por um dos pesquisadores que possui formação específica - Licenciatura em Educação Física.

As atividades foram previamente planejadas. No início das aulas, realizamos atividades de movimentação geral, para aquecimento e preparação do corpo, sem interesse em competição. Nessas atividades, os alunos interagiram o tempo todo e desenvolveram habilidades sociais por meio de brincadeiras direcionadas, como: pega-pega em diversas variações, duro e mole, barata no ar, seu lobo, dentre outras. Posteriormente, realizamos jogos que demandavam maior atenção no objeto, no amigo ou no professor: queimada tradicional, careca cabeludo com variações, lenço atrás, pular corda batendo-a, pular corda tradicionalmente (formato de jogo), pega-rabinhos, coelhinho sai da toca, dança das cadeiras cooperativa, alerta, esconde-esconde, amarelinha, seu lobo, gatinho manhoso, caça às cores na piscina (meio aquático), dentre outras.

Diante das limitações de espaço deste artigo, descrevemos e analisamos somente uma das atividades trabalhadas, a do "Seu lobo", escolhida por ser a atividade que mais chamou a atenção dos alunos - eles pediam para repeti-la ao final de todas as aulas. Nessa atividade, um aluno era escolhido para ser o lobo, no entanto sempre ficava para o professor tal papel. Os demais alunos deslocavam-se para um espaço determinado cantando a música Vamos passear na floresta, enquanto seu lobo não vem, repetindo-a até o momento que se aproximavam do "seu lobo" e perguntavam:

\footnotetext{
8 As avaliações foram realizadas pela equipe multidisciplinar da própria instituição escolar, somente os laudos médicos da especialidade de Neurologia tiveram origem externa. Nesses documentos - os quais estão arquivados na escola - não constam os critérios e os métodos utilizados por cada profissional, somente o parecer técnico, com a assinatura e o carimbo com número do respectivo Conselho profissional. Vale ressaltar que essas avaliações e esses laudos são condições para ingresso e permanência dos discentes na escola.
}

Práxis Educativa, Ponta Grossa, v. 12, n. 2, p. 551-569, maio/ago. 2017 Disponível em: <http://www.revistas2.uepg.br/index.php/praxiseducativa> 
"Está pronto, senhor lobo?". Quando a resposta era positiva, todos corriam para não serem pegos; se negativa, passeavam novamente na floresta. Decidimos pela regra de quem fosse capturado pelo lobo se tornar ajudante, assim nenhum aluno seria excluído.

Utilizamos o jogo da memória para as avaliações inicial e final, pois tornou-se pedagogicamente a mais viável para aplicação, tanto para a interação dos alunos, quanto para a organização dos pesquisadores, porque era fácil o manuseio e o entendimento dos alunos. A atenção foi verificada em 2 jogos de quebra-cabeças, cada um com 4 peças. Justificamos tal atividade por ser de provável conhecimento de todos os sujeitos, já que eles frequentaram, no ano anterior, a Educação Infantil, além de terem que se atentar para a organização correta de cada imagem.

A Figura 1 a seguir mostra como os jogos permaneciam antes dos alunos iniciarem a partida. Como é possível perceber, todas as 22 peças do jogo da memória estavam viradas para baixo e formariam 11 pares; já, nos quebra-cabeças, elas estavam viradas para cima, embaralhadas. Cada aluno foi instruído previamente sobre como proceder em sua realização; o professor só interagia quando o aluno questionava algo, mas não de maneira a solucionar o jogo, somente como nova explicação para persistirem.

Figura 1 - Formação inicial dos jogos nas avaliações

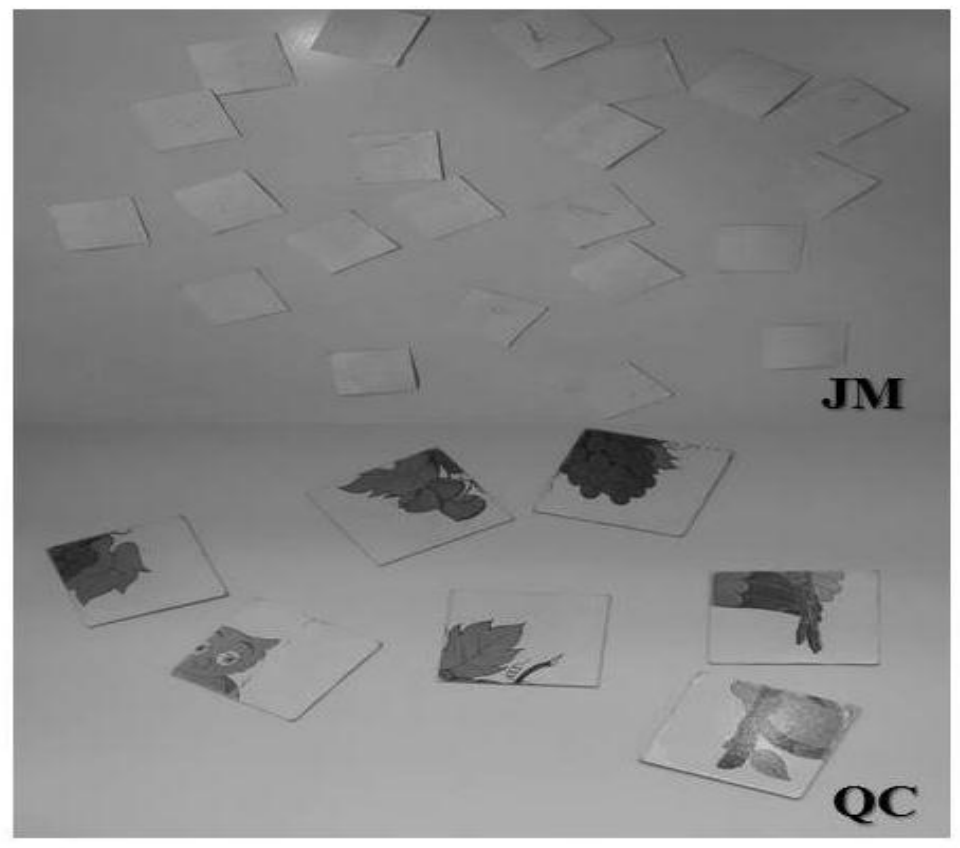

Fonte: Acervo dos autores.

JM: Jogo da memória; QC: Quebra-cabeça.

O objetivo final era que os 11 pares fossem encontrados no jogo da memória e, nos quebra-cabeças, duas imagens formadas de maneira dissociada - com as seguintes categorias semânticas: "a coruja é um animal e as uvas e morangos são frutas" - a primeira era visualmente mais fácil de ser realizada, mas a segunda possuía mais detalhes.

Os resultados de ambas as avaliações foram demonstrados por meio de imagens de cada momento e cada sujeito; posteriormente, foram analisados e discutidos qualitativamente de acordo com a literatura já apresentada neste texto. 
Nerli N. R. Mori, João Paulo P. Santos, Elsa M. Shimazaki, Lucyanne C. D. Goffi e Viviane G. C. Auada

- Apresentação e análise dos dados

A Figura 2 a seguir ilustra como os sujeitos terminaram as representações ao final da primeira avaliação, antes da intervenção. Os sujeitos denominados S1, S3, S4, S5 e S7 conseguiram encontrar todos os pares, demonstrando compreensão da atividade e uma boa memória visual, respeitando o tempo de cada um para entendimento do processo do jogo. Os sujeitos S2, S6 e S8 não demonstraram compreensão na atividade.

Galperin (2009) alerta para a necessidade de, nos processos escolares de cada criança, que elas sejam vistas como seres individuais, com ritmos de aprendizagem diferentes. As investigações desse autor apontam que alunos com deficiência intelectual possuem uma maneira progressiva de assimilação na formação de imagens, frequentemente insuficientes. Considerando tal fato, compreendemos que os alunos que não conseguiram assimilar as figuras iguais ainda estão iniciando o processo de desenvolvimento da memória visual para identificação das imagens, necessitando de mais tempo para compreensão.

As indicações iniciais remetem-nos às avaliações presentes no Quadro 1, de que os alunos que apresentaram maiores dificuldades na compreensão e na realização do jogo da memória também foram relatados em suas avaliações técnicas como pessoas com outros comprometimentos, além da deficiência intelectual em seu desenvolvimento, como a probabilidade de doença psiquiátrica $(\mathrm{S} 2)$, crise epilética e pouca socialização (S8). Esse fato alertou-nos para que, durante o processo pedagógico do estudo, nós os acompanhássemos de forma mais intensificada.

Observamos algumas informações nas falas desses sujeitos no decorrer da avaliação inicial que nos remetem a uma reflexão:

"Essa é a ovelha (identifica a imagem e vira outra diferente), esse é o cachorro (e mantém o par errado virado para cima, interagindo com as peças e as mantendo de forma desorganizada)" (S2).

"Chorro, dato, alinha" (reconhecia o signo, mas virava e desvirava as peças, sem formar par algum) (S6).

"Cadê a mamãe" (não se atentava para as peças, virava diferentes e dizia que eram iguais) (S8). 
Figura 2 - Avaliação inicial do Jogo da memória, sujeito a sujeito

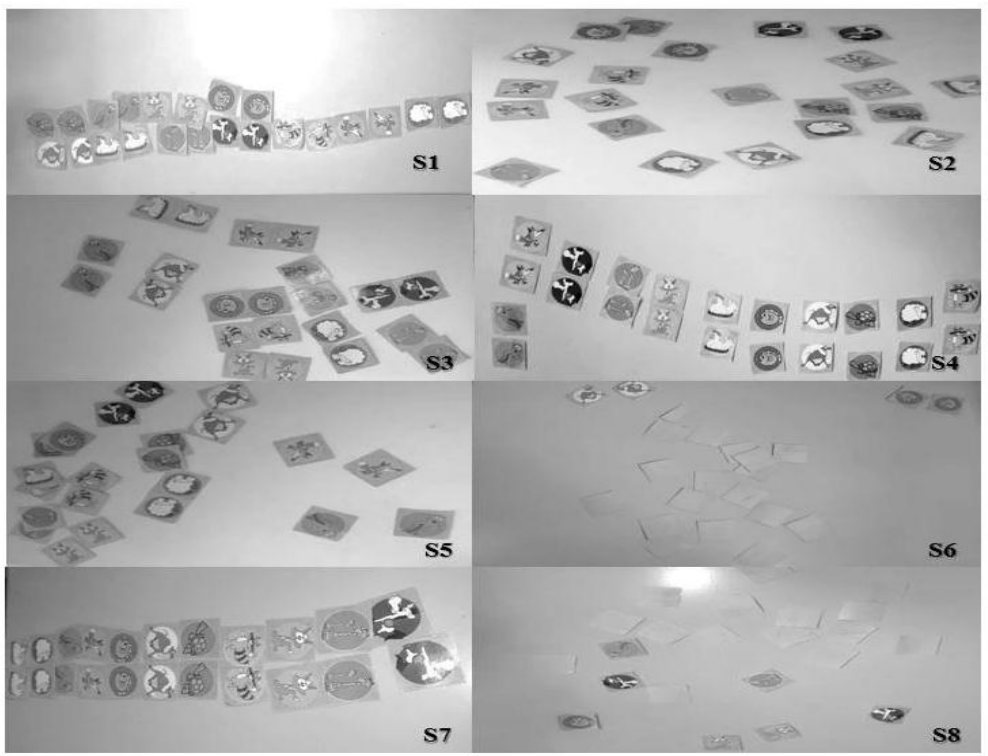

Fonte: Acervo dos autores.

Possivelmente, esses sujeitos não conseguiram entender os comandos da atividade proposta; demonstraram conhecimento das categorias semânticas, mas ainda não tinham organização mental para assimilar o conceito no espaço e tampouco memória visual para permanecerem com as peças viradas com as figuras para cima, mesmo quando o professor questionava se eram iguais e reafirmava que se a resposta fosse positiva era para deixá-las dessa forma. A nossa postura respalda-se em Vigotsky (2000) e Galperin (2009) quando afirmam que os erros devem ser deixados de lado, sendo a ênfase na valoração dos processos mentais que estão sendo elaborados.

Os sujeitos S1, S4 e S7 demonstraram organização metódica, pois perfilaram os pares para que fosse fácil sua identificação. Constatamos boa memória visual, independentemente do tempo de realização, e verificamos que são organizados espacialmente.

Quanto à permanência no jogo, os sujeitos S2, S6 e S8 desistiram do jogo, uma vez que não impusemos obrigatoriedade em sua conclusão. A participante S6 brincou durante o período todo com as peças, esfregando-as umas nas outras, colocando-as na boca, e sem explicação nenhuma, 11 minutos depois de iniciar, desmotivou-se e saiu. Quanto à atenção na atividade, a S8, durante mais da metade do tempo, não olhava para a atividade e fazia perguntas que não estavam relacionadas às atividades propostas; por fim, 11 minutos e 35 segundos após, pediu para sentar-se. Apesar de não desistir, a S2, que também não completou o jogo da memória, necessitou de maior período para entender que havia terminado; quando recebia alguma orientação do pesquisador, repetia as falas como, por exemplo: "S2, presta atenção se é igual??. Ela respondeu com a mesma pergunta se alto questionando: “S2, é igual?? (S2).

S2 concluiu a avaliação no momento que havia virado todas as peças, porém de forma desordenada formando apenas um par. Além da deficiência intelectual, a aluna possui indicativos técnicos de co-morbidades psiquiátricas, o que requer de suas análises um olhar diferenciado.

É possível identificar na Figura 3 a seguir os dados da segunda avaliação, após 4 meses de intervenção. 
Figura 3 - Avaliação final do Jogo da memória, sujeito a sujeito

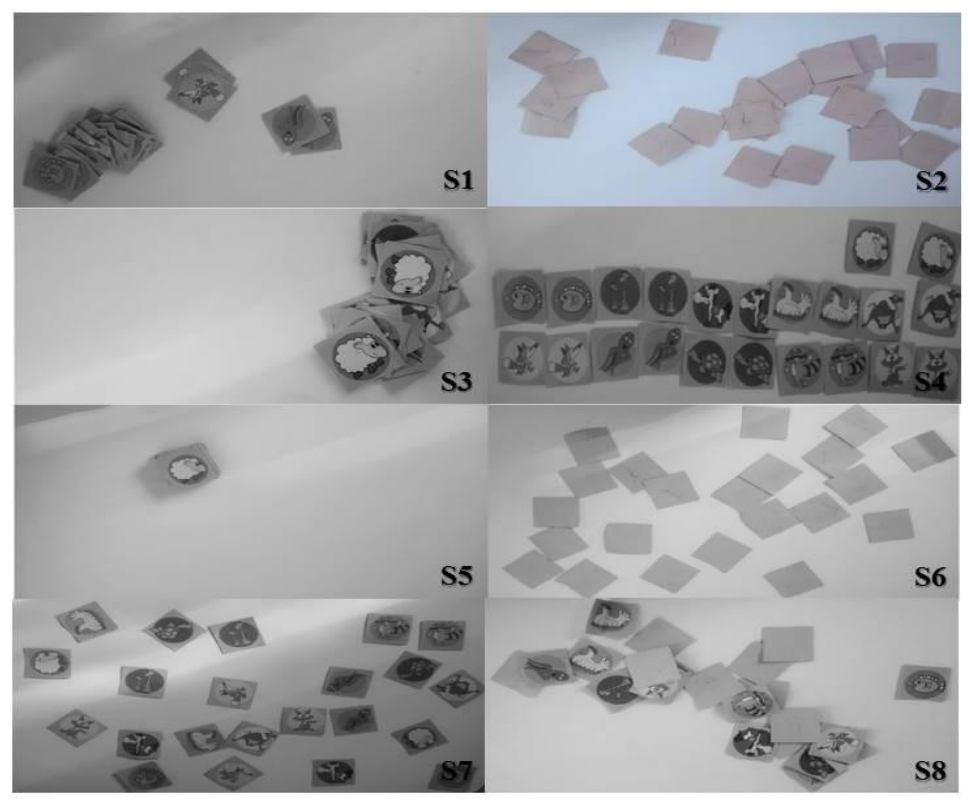

Fonte: Acervo dos autores.

Nossas discussões relacionam-se ao jogo da memória. Iniciamos citando o aluno S5, que gastou mais tempo, porém deixou as peças de forma mais organizada, o que nos leva a crer que, dessa vez, utilizou melhor de suas capacidades superiores, não no tempo de resolução, mas sim na forma, utilizando-se de uma nova estratégia, segurando as peças na mão. Ao final, elas estavam todas em uma coluna, e ele finalizou falando:

"Eu e minha irmã somos os mais espertos de casa" (S5).

S5 mostrou-se satisfeito com seu desenvolvimento no jogo. Com essa fala, ele aparenta entender que estava o tempo todo consciente em sua resolução e que se considera inteligente. Essa fala demonstra que, possivelmente, esse sujeito conhece suas habilidades e suas capacidades de desenvolvimento. Basei (2008) e Dainez (2014), fundamentados em Vigotsky, explicam que é importante a comunicação das crianças, inicialmente com as outras pessoas (social), posteriormente em atividades individuais, ou seja, as funções intrapsíquicas, sendo esse um processo absolutamente único no desenvolvimento psicointelectual.

As alunas S2, S6 e S8 (Figuras 2 e 3) não obtiveram melhoras no jogo da memória. Inicialmente permaneceram menos tempo no jogo e disseram que haviam terminado, mesmo o professor questionando "Lembram-se dos pares?". É possível entender que tal avaliação em seu segundo momento não foi atrativa a elas.

A atenção foi estudada por meio do quebra-cabeças (Figuras 4 e 5). Foi possível verificarmos que a dificuldade foi maior do que no jogo anterior, principalmente na imagem da uva e dos morangos, que necessitava de mais atenção porque possuía alguns traços bem parecidos. Os únicos que conseguiram organizar as duas imagens foram os sujeitos S1 e S7. Os sujeitos S4 e S5 encaixaram uma imagem "coruja" corretamente, mas não o fizeram com a "uva e os morangos". E os sujeitos S2, S3, S6 e S8 não montaram nenhum quebra-cabeça de forma correta. 
Jogos e brincadeiras no desenvolvimento da atenção e da memória em alunos com deficiência...

Figura 4 - Avaliação inicial do quebra-cabeças, sujeito a sujeito

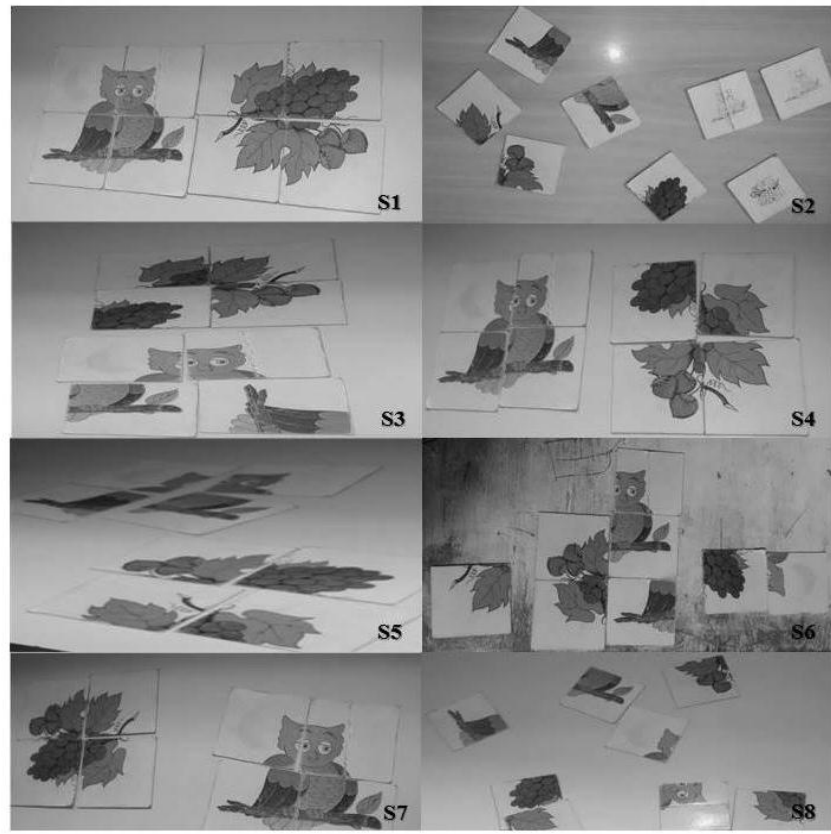

Fonte: Acervo dos autores.

Figura 5 - Avaliação final do quebra-cabeças, sujeito a sujeito

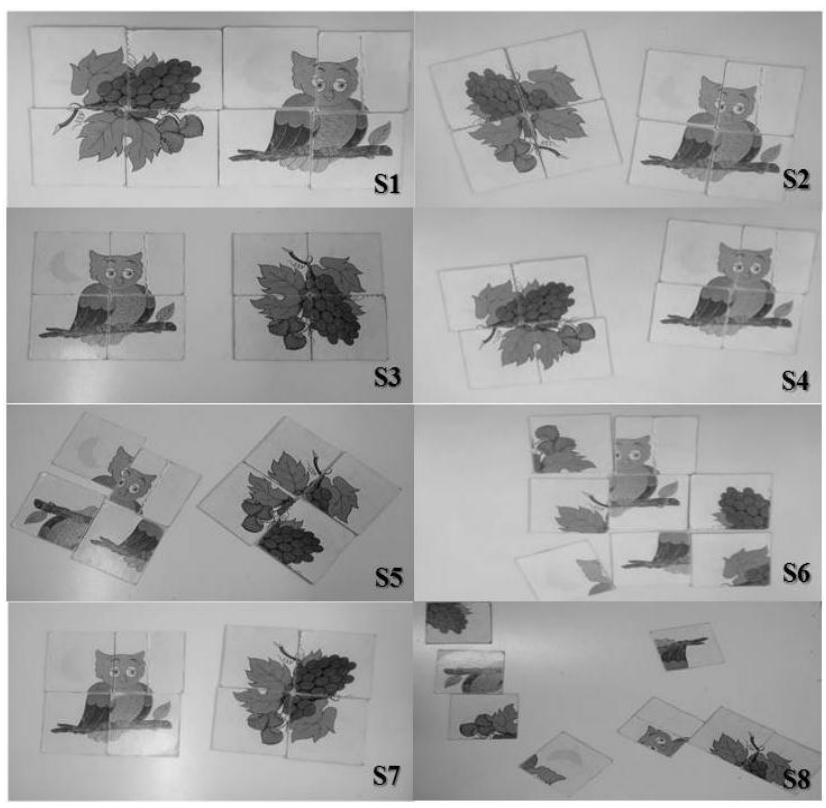

Fonte: Acervo dos autores.

Nas descrições de Leontiev (1988) e Vigotsky (2000, 2007), é possível entender que a relação com objetos possibilita, dentre várias coisas, a existência de um sujeito passivo, mas aberto a influências. Sugere uma possível abstração, e que tal processo tão rico indica conexões reais da criança com o mundo objetivo. No entanto, o autor explica que existem as condições internas que se manifestam de forma diferente de pessoa para pessoa, podendo ser influenciadas por inúmeros fatores, como os ambientais. 
Essas assertivas levam-nos ao entendimento de que, em relação à atenção, como grande parte dos sujeitos não se atentou ao objeto quebra-cabeças, diversos são os fatores que não os fizeram compreender a dinâmica, podendo ser as explicações do avaliador ou, simplesmente, o ambiente, a situação de avaliação, o clima ou outras influências que se opuseram à abstração e à atenção para o cumprimento da tarefa proposta. Durante o período de aplicação do projeto, realizamos mediações considerando os resultados da avaliação inicial e os dados de identificação dos sujeitos. Assim, durante a aplicação de todas as atividades, o professor mediava e era participante. Nos momentos que os alunos apresentavam mais dificuldades, eram realizadas intervenções como apoio intenso na mobilidade, na execução e/ou nas chamadas de atenção para o objetivo da atividade.

Durante a intervenção, podemos destacar algumas situações, como, por exemplo, o caso do sujeito S3, que demonstrou segurança em realizar as atividades, não fez nenhuma indagação, realizou com certa facilidade o jogo da memória, porém não conseguiu organizar nenhuma imagem, deixando-as totalmente descaracterizadas. Esse fato sugere que são necessárias várias mediações para o desenvolvimento real da atenção, pois os alunos podem acreditar ter cumprido a tarefa. O sujeito S8 mostrava-se ansioso o tempo todo, somente apresentou interação com instrumentos utilizados e nada mais. No caso da S2, houve a mesma dificuldade do jogo da memória, repetia o nome "coruja" o tempo todo, tanto que desvirou as demais imagens, mas não conseguiu obter atenção devida para a conclusão de nenhum quebra-cabeça, ela se desmotivou e pediu para ir brincar com os amigos.

Leontiev (1988) e Vigotsky (2000, 2007) esclarecem que o homem necessita, ao longo de toda a sua trajetória, dominar os objetos. Acreditamos que, inicialmente, os sujeitos apresentaram desmotivação porque não possuíam a devida atenção e motivação para completar o que era proposto, preferindo talvez jogos que possuíssem regras de comportamento por não estarem mais na fase exclusiva do brinquedo, em que a ação é o principal motivador.

Os alunos que não conseguiram resolver o quebra-cabeça antes e depois da intervenção foram os sujeitos S5, S6 e S8; os demais acertaram nos dois momentos ou somente no segundo. A mesma aluna S2, que apresentou dificuldade no jogo da memória, conseguiu realizar, na segunda vez, o quebra-cabeça inteiro, demonstrando que os experimentos pedagógicos com jogos e brincadeiras contribuíram em suas funções psicológicas superiores, em especial na atenção e na percepção, tão presente no jogo avaliado. O mesmo aconteceu com o sujeito S3, que só atingiu o objetivo após as aulas.

A utilização de instrumentos auxiliares e da fala causa grande impacto quando associada a atividades sensório-motoras, percepção e atenção, existindo conexões que auxiliam no desenvolvimento das funções psicológicas superiores (VIGOTSKY, 2007). No decorrer dos experimentos e nas avaliações, a fala foi um instrumento auxiliar frequente, e os estudos de Vigotsky nos fazem entender como a linguagem verbal funciona de forma interligada com a atenção e a percepção, resultando no avanço das crianças no jogo de quebra-cabeça.

Os alunos S5, S6 e S8 não conseguiram em nenhum momento atender às demandas do quebra-cabeça. Nas Figuras 4 e 5, podemos observar que as peças permaneceram praticamente iguais; além do mais, nesse jogo esses alunos permaneceram por mais tempo tentando resolver o problema. Verificamos que a motivação para permanecer na atividade foi maior; assim, recomendamos esse jogo para ser utilizado com crianças com deficiência intelectual.

O S5 demonstrou ter ótima oralidade e segurança em seus movimentos e atitudes. Ao ser indagado se estavam corretas as imagens, ele afirmou que sim, além de no jogo da memória conseguir com facilidade resolver a atividade. Notamos que, na avaliação inicial, S5 acertou a

Práxis Educativa, Ponta Grossa, v. 12, n. 2, p. 551-569, maio/ago. 2017 Disponível em: <http://www.revistas2.uepg.br/index.php/praxiseducativa > 
figura da coruja e errou a da uva e dos morangos, mas, no momento final, errou as duas. Nesse sentido, podemos verificar que a barreira para seu desenvolvimento na atenção e na percepção é puramente uma ânsia na resolução de problemas, talvez por se sentir em situação de avaliação. É possível inferir isso na fala com a professora regente (alfabetizadora), com suas próprias conclusões, após chegar à sala e fazer a segunda avaliação do quebra-cabeça.

\section{"O professor vê quem termina mais rápido." (S5)}

Os sujeitos S6 e S8 tiveram dificuldades no jogo da memória e no quebra-cabeça em ambos os momentos de avaliação. Ressaltamos que, dentre todos os alunos, eles são os que apresentam linguagem mais comprometida, usando palavras soltas, com dificuldade em formar frases, sendo difícil a comunicação com eles.

Vigotsky (2007), baseado em Stern, explica que as crianças pequenas, que estão na fase de "objetos" isolados, permanecem com mais facilidade atentas a objetos dinâmicos, pois, nesse momento, suas expectativas são atendidas pelo sentido da visão. No entanto, em momento posterior à essa fase, a linguagem passa a ser o instrumento mediador principal e suas necessidades e suas expectativas agora serão atendidas por meio da linguagem. Nesse caso, as crianças que apresentam dificuldades no desenvolvimento da fala, restringindo a significação do mundo apenas pelo campo da visão, tendem a apresentar atraso no desenvolvimento cognitivo.

\section{Considerações finais}

As pesquisas educacionais que priorizam a reflexão da prática pedagógica por meio do movimento dialético entre o fazer e o pensar são necessárias a todos os profissionais da educação. É nesse sentido que reiteramos a importância desta pesquisa-ação, ao discutirmos as contribuições dos jogos e das brincadeiras para o processo de desenvolvimento da atenção e da memória em alunos identificados com deficiência intelectual na primeira etapa do primeiro ciclo do Ensino Fundamental. Assim, com respaldo da Teoria Histórico-Cultural, esta pesquisa permitiu refletirmos sobre as possibilidades dos conteúdos da Educação Física - jogos e brincadeira - se constituírem como um instrumento para o desenvolvimento das funções psicológicas superiores das crianças referidas.

Os jogos e as brincadeiras constituíram-se como conteúdos eficazes no processo pedagógico em relação à memória e, em especial, à atenção. No jogo da memória, em que analisamos a princípio a memória visual, os alunos que não conseguiram realizar o jogo no início também tiveram dificuldades ao término, mas todos os outros concluíram na segunda análise com mais facilidade. Todavia, a intervenção com o quebra-cabeça apresentou resultados bem diferentes, pois dois alunos que não conseguiram realizar a atividade proposta na avaliação préinterventiva, após o experimento, apresentaram avanços significativos ao encaixarem corretamente todas as peças do jogo, e os demais sujeitos da pesquisa, que já haviam apresentado resultados positivos na avaliação inicial, o fizeram novamente na análise pós-intervenção.

No geral, destacamos que somente duas alunas não apresentaram nenhum avanço posteriormente à intervenção, e a elas sugerimos que novas avaliações fossem realizadas, talvez mais simplificadas ou, até mesmo, um período maior de atividades/intervenções, pois ambas se mostravam motivadas nas aulas. Nesse sentido, observamos que a Educação Física escolar contempla os conteúdos de jogos e brincadeiras, e a Educação Física adaptada com objetivo de incluir os sujeitos considerando suas limitações possibilita o desenvolvimento das pessoas com deficiência intelectual. Assim, os benefícios para esse grupo podem ser significativos no tocante à formação e ao desenvolvimento das funções psicológicas superiores.

Práxis Educativa, Ponta Grossa, v. 12, n. 2, p. 551-569, maio/ago. 2017 Disponível em: <http://www.revistas2.uepg.br/index.php/praxiseducativa> 
Nerli N. R. Mori, João Paulo P. Santos, Elsa M. Shimazaki, Lucyanne C. D. Goffi e Viviane G. C. Auada

Enfatizamos que a memória e a atenção são habilidades requeridas para a apropriação e o desenvolvimento da leitura e da escrita. Dessa forma, a Educação Física tem como princípio discutir os conteúdos específicos presentes na cultura corporal de movimento (esportes, ginásticas, danças, lutas e jogos e brincadeiras), mas pode trabalhar em conjunto com as demais disciplinas na formação do sujeito alfabetizado e letrado, capaz de viver cada vez mais incluso em uma sociedade estratificada que, em sua essência, não oferece a todos as mesmas possibilidades de acesso aos bens culturais e, por conseguinte, também não oferece a todos as mesmas possibilidades para desenvolvimento das funções psicológicas superiores dos humanos.

\section{Referências}

ANDRÉ, M. H.; HASTIE, P.; ARAÚJO, R. F. O desenvolvimento da compreensão holística do jogo por meio da criação do jogo. Revista Brasileira de Ciências do Esporte, Curitiba, v. 37, n. 4, p. 323-332, 2015. DOI: 10.1016/j.rbce.2015.08.001

ARAÚJO, P. F.; SILVA, R. F. Aspectos gerais da deficiência física e suas implicações no dia a dia. In: SHIMAZAKI, E. M.; PACHECO, E. R. Deficiência e inclusão escolar. Maringá: EDUEM, 2012. p. 107-127.

AUADA, V. G. C. Apropriação de conceitos científicos e processo de letramento em jovens e adultos com deficiência intelectual. 2015. 169 f. Dissertação (Mestrado em Educação) - Universidade Estadual de Maringá, Maringá, 2015.

AZEVEDO, F. C. Inclusão de alunos deficientes intelectuais e o processo de alfabetização. 2016. 138 f. Dissertação (Mestrado em Educação) - Universidade Estadual de Maringá, Maringá, 2016.

BASEI, A. P. A Educação Física na Educação Infantil: a importância do movimentar-se e suas contribuições no desenvolvimento da criança. Revista Iberoamericana de Educación [online], n. $47 / 3$, p. $1-12$, out. 2008.

BRASIL. Ministério da Saúde. Conselho Nacional de Saúde. Resolução No 466, de 12 de dezembro de 2012. Diário Oficial da União, Poder Executivo, Brasília, DF, 13 jun. 2013. Seção 1, n. 112, p. 59-62.

BRASIL. Ministério da Saúde. Conselho Nacional de Saúde. Resolução No 510, de 7 de abril de 2016. Diário Oficial da União, Poder Executivo, Brasília, DF, 24 maio 2016. Seção 1, n. 98, p. 44-46.

CAILLOIS, R. Los juegos y los hombres - la máscara y el vértigo. México: Fondo da Cultura Económica, 1994.

CÁRNIO, M. S.; SHIMAZAKI, E. M. Letramento e alfabetização das pessoas com deficiência intelectual. Revista Teoria e Prática da Educação, Maringá, v. 14, n. 1, p. 143-151, jan./abr. 2011.

CASTRO, E. M. Atividade física: adaptada. 2. ed. Ribeirão Preto: Tecmedd, 2005.

Práxis Educativa, Ponta Grossa, v. 12, n. 2, p. 551-569, maio/ago. 2017 Disponível em: <http://www.revistas2.uepg.br/index.php/praxiseducativa > 
Jogos e brincadeiras no desenvolvimento da atenção e da memória em alunos com deficiência...

COSTA, A. M.; SOUSA, S. B. Educação Física e esporte adaptado: história, avanços e retrocessos em relação aos princípios da integração/inclusão e perspectivas para o século XX. Revista Brasileira de Ciências do Esporte, Campinas, v. 25, n. 3, p. 27-42, 2004.

DAINEZ, D. Constituição humana, deficiência e educação: problematizando o conceito de compensação na perspectiva histórico-cultural. 2014. 125 f. Tese (Doutorado em Educação) Universidade Estadual de Campinas, Faculdade de Educação, Campinas, 2014.

ELKONIN, D. Psicologia do jogo. São Paulo: Martins Fontes, 1998.

FARIA, M. de O. A teoria histórico-cultural e a brincadeira: (re)pensando a educação infantil a partir dos autores contemporâneos. 2016. 184 f. Dissertação (Mestrado em Educação) Universidade Federal de São Carlos, São Carlos, 2016.

FREIRE, J. B. Educação de corpo inteiro-teoria e prática da Educação Física. 4. ed. São Paulo: Scipione, 1989.

GALPERIN, P. Y. La formación de la imagénes sensoriais y los conceptos. In: ROJAS, Q. L.; SOLOVIEIRA, Y. Las funciones psicológicas em el desarrollo del niño. México: Trillas, 2009. p. 64-75.

GOFFI, L. C. D.; MORI, N. N. R. O brincar das crianças com necessidades educacionais especiais no intervalo escolar. In: MORI, N. N. R.; GOULART, A. M. P. L. Educação e inclusão. Maringá: Eduem, 2010. p. 97-120.

HUIZINGA, J. Homo Ludens: o jogo como elemento da cultura. São Paulo: Perspectiva, 1980.

JUKOVSKAIA, R. I. La educación del niño en el juego. Habana: Pueblo y Educación, 1978.

LEONTIEV, A. N. O desenvolvimento do psiquismo. Lisboa: Livros Horizonte, 1978.

LEONTIEV, A. N. Os princípios psicológicos da brincadeira pré-escolar. In: VIGOTSKI, L. S.; LURIA, A. R.; LEONTIEV, A. N. Linguagem, desenvolvimento e aprendizagem. 3. ed. São Paulo: Ícone, 1988. p. 103-117.

LEONTIEV, A. N. Os princípios psicológicos da brincadeira pré-escolar. In: VYGOTSKY, L. S.; LURIA, A. R.; LEONTIEV, A. N. Linguagem, desenvolvimento e aprendizagem. Tradução Maria da Penha Villalobos. São Paulo: Icone, 2006. p. 119-142.

LURIA, A. R. Vigotski. In: VIGOTSKI, L. S.; LURIA, A. R.; LEONTIEV, A. N. Linguagem, desenvolvimento e aprendizagem. 14. ed. São Paulo: Ícone, 2016. p. 21-38.

MARCOLINO, S.; BARROS, F. C. O. M. de; MELLO, S. A. A teoria do jogo de Elkonin e a educação infantil. Revista Quadrimestral da Associação Brasileira de Psicologia Escolar e Educacional, São Paulo, v. 18, n. 1, p. 97-104, jan./abr. 2014. DOI: 10.1590/s141385572014000100010

PARANÁ. Câmara da Educação Infantil e do Ensino Fundamental e Câmara do Ensino Médio e da Educação Profissional Técnica de Nível Médio. Parecer CEE/CEIF/CEMEP 07/14. 2014. Disponível

em: 
Nerli N. R. Mori, João Paulo P. Santos, Elsa M. Shimazaki, Lucyanne C. D. Goffi e Viviane G. C. Auada

<http://www.educadores.diaadia.pr.gov.br/arquivos/File/ed_especial/parecer_07_14.pdf>.

Acesso em: 20 jan. 2017.

SILVA, R. F.; SEABRA JÚNIOR, L.; ARAÚJO, P. F. Educação Física adaptada no Brasil: da história a inclusão educacional. São Paulo: Phorte, 2008.

SOARES, C. L. Educação Física escolar: conhecimento e especificidade. Revista Paulista de Educação Física, São Paulo, supl. n. 2, p. 6-12, 1996.

UNESCO. Carta Internacional da Educação Física e Esporte. Lisboa: Comissão Nacional da UNESCO de Portugal. 1978. Disponível em: <http://unesdoc.unesco.org/images/0021/002164/216489por.pdf>. Acesso em: 5 fev. 2016.

VENÂNCIO, L.; DARIDO, S. C. A Educação Física escolar e o projeto político pedagógico: um processo de construção coletiva a partir da pesquisa-ação. Revista Brasileira de Educação Física e Esporte, São Paulo, v. 26, n. 1, p. 97-109, jan./mar. 2012. DOI: 10.1590/S180755092012000100010

VYGOTSKY. Obras Escogidas - V: Fundamentos de defectología. Madrid: Visor Distribuiciones S. A., 1997.

VYGOTSKY, L. S. Obras Escogidas - III: Problemas del desarrollo de la psique. 2. ed. Madrid: Visor Distribuiciones S. A., 2000.

VYGOTSKY, L. S. A Formação social da mente. São Paulo: Martins Fontes, 2003.

VYGOTSKY; L. S. A formação social da mente: o desenvolvimento dos processos psicológicos superiores. 7. ed. São Paulo: Martins Fontes, 2007.

Recebido em 31/05/2016

Versão corrigida recebida em 04/04/2017

Aceito em 20/04/2017

Práxis Educativa, Ponta Grossa, v. 12, n. 2, p. 551-569, maio/ago. 2017 Disponível em: <http://www.revistas2.uepg.br/index.php/praxiseducativa > 